\title{
ANALISIS STANDAR MUTU, DISKON DAN LOKASI TERHADAP KEPUTUSAN PEMBELIAN KEMBALI BUKU PENDAMPING MAESTRO (Studi pada Sekolah Dasar di Kabupaten Wonogiri)
}

\author{
Endah Prastiwi ${ }^{1}$, Djumali $^{2}$, Rochmi Widayanti $^{3}$ \\ ${ }^{123}$ Jurusan Manajemen Fakultas Ekonomi Universitas Islam Batik Surakarta \\ Email: ${ }^{1}$ endahrasti@gmail.com
}

\begin{abstract}
Referring to government regulations regarding the regulation of companion books used in schools, this forces the book producers to innovate in order to produce quality and acceptable books on the market. One of the companion book producers in Central Java is CV Hasan Pratama with the brand Maestro. This study has the purpose to investigate the effect of quality standards, discounts and location on Maestro's companion book repurchase decisions. Samples were taken randomly as many as 115 respondents, but only 99 samples could be used. Research uses a type of quantitative research, and using multiple linear regression analysis techniques. Data was collected by giving questionnaires to teachers who taught elementary school level in Wonogiri District. The results of this study prove that quality standards, discounts and locations have a simultaneous effect on product repurchase decisions. But partially the discount variable has a negative effect on product repurchase decisions.
\end{abstract}

Keywords: quality standards, discounts, location, repurchase decision

\section{PENDAHULUAN}

Keberadaan konsumen sangat penting bagi perusahaan, karena konsumen merupakan sasaran utama perusahaan dalam memasarkan produknya. Tjiptono (2015: 76) bisnis bertujuan untuk menciptakan kepuasan pelanggan. Dimana kepuasan pelanggan dapat menciptakan hubungan harmonis antara perusahaan dengan pelanggan.

Tahun 1990-an perusahaan mulai menyadari pentingnya membuat produk yang tidak hanya berkonsentrasi pada produk dan teknologi yang digunakan saja, namun juga berwawasan pelanggan dan mementingkan pelanggan (customer oriented and driven). Hal ini dikarenakan adanya perusahaan yang memproduksi produknya hanya berorientasi pada produk yang dihasilkan saja, tanpa memperhatikan masukan dari pelanggan (Sudaryono, 2016: 36).

Peningkatan mutu produk berorientasi pada pelanggan ditempuh melalui inovasi dan diferensiasi produk. Dengan produk yang bermutu dan strategi pemasaran yang tepat diharapkan dapat meningkatkan penjualan. Sudaryono (2016: 53) menjelaskan produk yang menyajikan mutu, kinerja terbaik dan berbagai keunggulan lainya cenderung akan lebih dipilih oleh konsumen. Widyastuti dan Ariyanti (2014) standar mutu merupakan instrumen utama dalam rangka meningkatkan daya saing suatu produk. 
Pemberlakuan standar mutu tidak hanya berlaku pada produk makanan, mebel, fashion, dan jasa saja, namun berlaku juga bagi produk buku pelajaran yang digunakan di sekolah. Contoh buku LKS (Lembar Kerja Siswa), pada jaman dahulu LKS merupakan primadona bagi guru maupun siswa. Namun sesuai Peraturan Menteri Pendidikan dan Kebudayaan No. 75 Tahun 2016 tentang komite sekolah pasal 12 ayat 1, maka penjualan LKS di sekolah mulai dilarang meski buku ini tetap dicari keberadaaanya oleh guru maupun siswa.

Mengacu pada UU No. 3 Tahun 2017, maka buku LKS berevolusi menjadi buku pendamping. Evolusi dilakukan secara menyeluruh baik dari segi fisik maupun isi materi buku, salah satu cara yang ditetapkan yakni penerapan standar mutu.

Standar mutu termasuk dalam salah satu variabel yang sangat mempengaruhi keputusan konsumen dalam pemilihan produk atau jasa yang akan digunakan (Muhajir, 2016). Fahmi (2016: 50) mutu dapat diartikan sebagai keadaan dimana konsumen merasa sangat puas terhadap suatu produk. Penelitian terdahulu oleh Christanto (2018) berkesimpulan akan pentingnya perancangan standar mutu produk yang ditetapkan. Persamaan penelitian Christanto (2018) dengan penelitian ini yaitu sama-sama meneliti pentingnya penetapan standar mutu produk. Perbedaaanya, penelitian ini terfokus pada pengaruh standar mutu terhadap keputusan pembelian kembali. Selain standar mutu produk, hal lain yang dipertimbangkan dalam keputusan pembelian kembali produk adalah strategi pemasaran yang ditetapkan. Salah satunya yakni dengan pemberian diskon.

Diskon memiliki daya tarik tersendiri bagi konsumen ketika memilah suatu produk. Putra, Kumadji dan Yulianto (2016) diskon berpengaruh secara signifikan terhadap keputusan pembelian suatu produk. Namun penelitian ini tidak sejalan dengan penelitian Anggraeni (2016) yang menyatakan bahwa diskon tidak berpengaruh terhadap keputusan pembelian suatu produk. Perbedaaan penelitian ini dengan penelitian sebelumnya, produk yang diteliti pada penelitian ini memiliki life cyle produk yang cenderung singkat, dan segmen pasar yang cenderung sempit.

Faktor lain yang diperhatikan dalam upaya peningkatan penjualan adalah lokasi. Fahmi (2016: 42) menjabarkan bahwa lokasi dipercaya sangat memberikan pengaruh pada tingkat penjualan suatu perusahaan, karena lokasi dianggap sebagai investasi jangka panjang bagi perusahaan. Penelitian Tyas dan Setiawan (2012) menyatakan bahwa lokasi berpengaruh terhadap keputusan konsumen. Perbedaaan penelitian ini dengan penelitian sebelumnya yakni dalam penelitian ini melibatkan salah satu peranan aplikasi digital yang digunakan untuk mencari lokasi, yakni GPS.

\section{METODE PENELITIAN}

Penelitian ini tergolong dalam jenis penelitian kuantitatif. Populasi yang diambil adalah guru di sekolah dasar yang pernah menggunakan dan membeli buku pendamping Maestro di Kabupaten Wonogiri. Sampel yang digunakan sebanyak 115 responden, namun yang bisa digunakan hanya 99 responden karena terdapat biasdata pada 16 responden yang disortir. Pengolahan data menggunakan teknik analisis regresi linear berganda. 


\section{ANALISIS DATA}

\subsection{Pengujian Asumsi Klasik}

\section{a. Pengujian normalitas}

Ghozali (2013: 110) uji normalitas dilakukan menggunakan dengan 2 metode, yakni metode statistik dan metode grafik.

1) Metode statistik

Berikut tabel uji statistik dalam penelitian ini:

\section{Tabel 1.}

Hasil Uji Kolmogrov-Smirnov Test

One-Sample Kolmogorov-Smirnov Test

\begin{tabular}{|ll|r|}
\hline & & $\begin{array}{r}\text { Unstandardize } \\
\text { d Residual }\end{array}$ \\
\hline $\mathrm{N}$ & Mean & 99 \\
Normal Parameters $^{\mathrm{a}, \mathrm{b}}$ & Std. &, 0000000 \\
& Deviation & 1,93245084 \\
Most Extreme Differences & Absolute &, 079 \\
& Positive &, 073 \\
Test Statistic & Negative &,- 079 \\
Asymp. Sig. (2-tailed) & &, 079 \\
\end{tabular}

a. Test distribution is Normal.

Sumber:

data primer diolah dengan SPSS 23 Th 2019

Mengacu pada tabel diatas diketahui nilai Asymp. Sig. (2-tailed) 0,136>0,05, yang artinya data tersebut terdistribusi normal.

2) Metode grafik

Berikut ini tabel P-Plot yang digunakan.

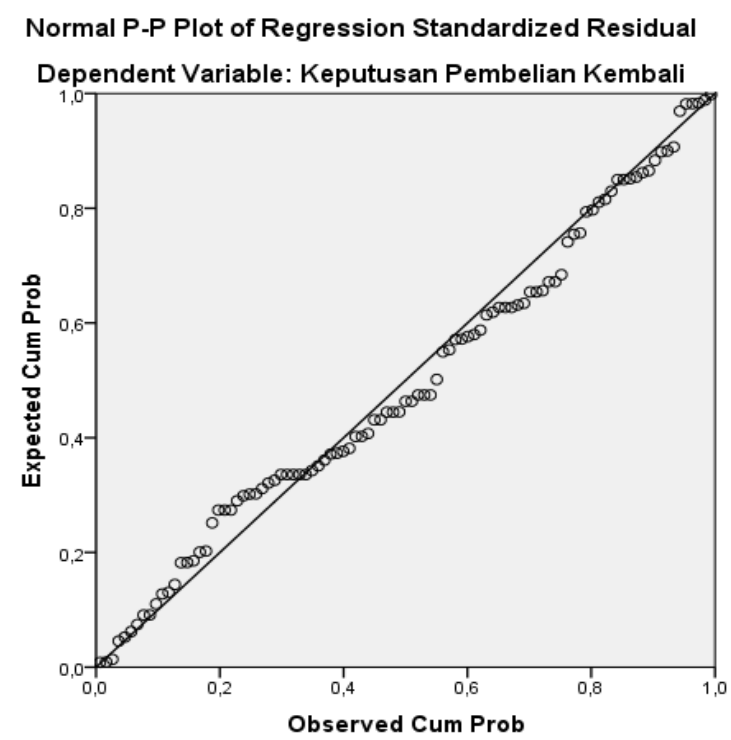

Gambar 1. Hasil Uji Normalitas (P-Plot) 
Gambar diatas menjelaskan hasil uji normalitas dengan P-Plot menghasilkan data berupa titik yang mengikuti garis diagonal. Artinya data tersebut terdistribusi secara normal.

\section{b. Pengujian multikolinearitas}

Tabel 2. Hasil Uji Multikolinearitas

\begin{tabular}{llll}
\hline Variabel & Tolerance & VIF & \multicolumn{2}{l}{ Kesimpulan } \\
\hline $\begin{array}{l}\text { Standar } \\
\text { Mutu }\left(\mathrm{X}_{1}\right)\end{array}$ & 0,957 & 1,045 & $\begin{array}{l}\text { Tidak terjadi } \\
\text { Multikolinearitas }\end{array}$ \\
\hline $\begin{array}{l}\text { Diskon } \\
\left(\mathrm{X}_{2}\right)\end{array}$ & 0,969 & 1,032 & $\begin{array}{l}\text { Tidak terjadi } \\
\text { Multikolineraritas }\end{array}$ \\
\hline $\begin{array}{l}\text { Lokasi } \\
\left(\mathrm{X}_{3}\right)\end{array}$ & 0,940 & 1,064 & $\begin{array}{l}\text { Tidak terjadi } \\
\text { Multikolinearitas }\end{array}$ \\
\hline
\end{tabular}

Berdasarkan penelitian diatas nilai toleran yang dihasilkan lebih dari 0,10 dan nilai VIF $<10,00$. Artinya tidak terdapat multikolinearitas.

\section{c. Pengujian Heterokedastisitas}

Pengujian heterokedastisitas dapat menggunakan metode scatterplot ataupun dapat menggunakan metode glejser.

Tabel 3. Hasil Uji Heterokedastisitas

\begin{tabular}{|c|c|c|c|c|c|}
\hline \multirow[b]{2}{*}{ Model } & \multicolumn{2}{|c|}{$\begin{array}{l}\text { Unstandardize } \\
\text { d Coefficients }\end{array}$} & \multirow{2}{*}{$\begin{array}{c}\begin{array}{c}\text { Standa } \\
\text { rdized } \\
\text { Coeffici } \\
\text { ents }\end{array} \\
\text { Beta } \\
\end{array}$} & \multirow[b]{2}{*}{$\mathrm{T}$} & \multirow[b]{2}{*}{ Sig. } \\
\hline & B & $\begin{array}{l}\text { Std. } \\
\text { Error }\end{array}$ & & & \\
\hline $\begin{array}{ll}1 & \text { (Consta- } \\
\text { nt) }\end{array}$ & 331 & 1,696 & & ,195 & ,846 \\
\hline $\begin{array}{l}\text { Standar } \\
\text { Mutu }\end{array}$ & ,097 & ,057 & 175 & 1,707 & ,091 \\
\hline Diskon & ,036 & ,048 & ,076 & ,748 & ,456 \\
\hline Lokasi & -086 & ,061 &,- 146 & $-1,410$ & ,162 \\
\hline
\end{tabular}

Sesuai data diatas diketahui koefisien standar mutu sebesar 0,91>0,05, diskon 0,456>0,05, dan lokasi 0,162>0,05 artinya ketiga variabel tersebut terbebas dari gejala heterokedastisitas.

\section{d. Auto Korelasi}

Diuji menggunakan metode runtest 
Tabel 4. Hasil Uji Autokorelasi

\section{Runs Test}

\begin{tabular}{|l|r|}
\hline & $\begin{array}{c}\text { Unstandardized } \\
\text { Residual }\end{array}$ \\
\hline Test Value $^{\mathrm{a}}$ &,- 17987 \\
Cases < Test Value & 49 \\
Cases $>=$ Test Value & 50 \\
Total Cases & 99 \\
Number of Runs & 45 \\
Z & $-1,110$ \\
Asymp. Sig. (2-tailed) &, 267 \\
\hline a. Median & \\
Sumber: & \\
Data primer diolah dengan SPSS 23 Th 2019
\end{tabular}

Sesuai tabel diatas dapat diketahui bahwa nilai Asymp. Sig. (2-tailed) 0,267>0,05, maka kesimpulannya tidak terdapat masalah autokorelasi.

\subsection{Pengujian Analisis Data}

Tabel 5. Hasil Uji Regresi Berganda

\begin{tabular}{lllll}
\hline Model & $\mathrm{B}$ & $\mathrm{T}_{\text {hitung }}$ & Sig & Keterangan \\
\hline Constant & 8,953 & 3,298 & 0,001 & \\
$\begin{array}{l}\text { Standar } \\
\text { Mutu }\end{array}$ & 0,347 & 3,823 & 0,000 & Signifikan \\
Diskon & $-0,027$ & $-0,350$ & 0,727 & $\begin{array}{l}\text { Tidak } \\
\text { Signifikan }\end{array}$ \\
Lokasi & 0,280 & 2,856 & 0,005 & Signifikan \\
$\mathrm{F}_{\text {hitung }}$ & 9,344 & $(0,000)$ & & \\
\hline $\mathrm{R}^{2}$ & 0,228 & & & \\
Adjusted & 0,203 & & & \\
$\mathrm{R}^{2}$ & & & & \\
\hline \multicolumn{4}{c}{ Sumber data: diolah dengan SPSS Th 2019 }
\end{tabular}

Model regresi yang dihasilkan yaitu:

$Y=8,953+0,347 X_{1}+(-0,027) X_{2}+0,280 X_{3}+E$

Keterangan:

1. Pada tabel diatas terlihat konstanta sebesar 8,953 (positif). Artinya apabila standar mutu, diskon dan lokasi bernilai 0, maka keputusan pembelian kembali akan meningkat sebesar 8,953 .

2. Standar mutu bernilai positif sebesar 0,347. Artinya standar mutu produk mewakili pengaruh positif terhadap keputusan pembelian kembali buku pendamping Maestro.

3. Diskon bernilai -0,027 (negatif), artinya apabila diskonmengalami penurunan sebesar -0,027 maka keputusan pembelian kembali juga mengalami penurunan.

4. Lokasi bernilai positif 0,280 (positif). Artinya lokasi berpengaruh positif terhadap keputusan pembelian kembali.

\subsection{Uji hipotesis}

Teknik untuk menguji hipotesis menggunakan uji regresi linear berganda, uji $\mathrm{F}$, uji $\mathrm{t}$ dan koefisien determinasi $\left(\mathrm{R}^{2}\right)$ dengan kesimpulan sebagai berikut: 
a. Uji F

Dilihat dari tabel 5 hasil uji analisa uji $\mathrm{F}$ didapat besaran nilai $\mathrm{F}_{\text {hitung }}$ 9,344 sedangkan nilai signifikansi yang dihasilkan $0,000<0,05$. Artinya model regresi yang digunakan sudah memenuhi syarat berpengaruh simultan. Atau dengan kata lain standar mutu, diskon dan lokasi berpengaruh secara simultan (secara bersama-sama) terhadap keputusan pembelian kembali buku pendamping Maestro.

b. Uji t

Tabel 5 menunjukkan bahwa:

1) Analisis uji t pada variabel standar mutu memiliki nilai $t_{\text {hitung }}$ sebesar 3,823 serta nilai probabilitasnya $0,00<0,05$, artinya terdapat pengaruh signifikan variabel standar mutu terhdap keputusan pembelian kembali buku pendamping Maestro.

2) Analisis uji t pada variabel diskon menunjukkan nilai $t_{\text {hitung }}$ sebesar $-0,350$ serta nilai probabilitas 0,727>0,05, artinya tidak terdapat pengaruh signifikan antara variabel diskon terhadap keputusan pembelian kembali buku pendamping Maestro.

3) Analisis uji t pada variabel Lokasi memiliki nilai $t_{\text {hitung }}$ sebesar 2,856 serta nilai probabilitasnya $0,005<0,05$, artinya terdapat pengaruh signifikan antara variabel lokasi terhadap keputusan pembelian kembali buku pendamping Maestro.

\subsection{Koefisien Determinasi (R2)}

Pada tabel 5 terlihat nilai $\mathrm{R}^{2}$ sebesar 0,228 (28,8\%), artinya pengaruh variabel standar mutu, diskon dan lokasi terhadap keputusan pembelian kembali buku pendamping Maestro sebesar $28,8 \%$, sehingga untuk $71,2 \%$ lainnya terpengaruh oleh variabel-variabel lain, dimana variabel tersebut tidak diteliti dalam penelitian ini.

\section{PEMBAHASAN}

\section{Pengaruh standar mutu $\left(\mathrm{X}_{1}\right)$ terhadap keputusan pembelian kembali buku pendamping Maestro (Y)}

Standar mutu berpengaruh terhadap keputusan pembelian kembali. Penelitian ini sesuai dengan penelitian Muhajir (2016) menyatakan bahwa standar mutu berpengaruh secara signifikan terhadap keputusan konsumen dalam menggunakan layanan jasa. Penelitian ini juga sejalan dengan Christanto (2018) tentang pentingnya perancangan manajemen mutu untuk menghasilkan produk yang bermutu tinggi.

CV Hasan Pratama selaku produsen buku pendamping Maestro senantiasa menjaga standar mutu produk yang dihasilan dengan memperhatikan quality control pada setiap bagian produksi agar sesuai dengan standar mutu produk yang ditetapkan, mulai dari persiapan bahan baku sampai pada buku jadi. Hal ini bertujuan agar konsumen dapat melakukan pembelian ulang setelah mengetahui keterjaminan standar mutu produk. 
Pengaruh diskon $\left(\mathrm{X}_{2}\right)$ terhadap keputusan pembelian kembali buku pendamping Maestro (Y)

Variabel diskon tidak berpengaruh terhadap keputusan pembelian kembali. Penelitian ini sejalan dengan penelitian Satyo dan Suprihhadi (2013) diskon berpengaruh terhadap keputusan pembelian. Akan tetapi penelitian ini tidak sejalan dengan penelitian Putra, Kumadji dan Yulianto (2016) menyatakan bahwa diskon tidak berpengaruh terhadap keputusan pembelian produk.

Bagi konsumen yang mementingkan kualitas produk maka mereka cenderung tidak terpengaruh dengan penawaran diskon yang diberikan dalam rangka keputusan pembelian kembali suatu produk. Hal ini dibuktikan dalam hasil penelitian ini yang membuktikan bahwa diskon tidak berpengaruh terhadap keputusan pembelian kembali buku pendamping Maestro.

Produk yang diteliti dalam penelitian Suprihhadi merupakan produk yang memiliki life cyle yang lebih lama, sehingga diskon dapat mempengaruhi dalam keputusan pembelian kembali produk tersebut. Sedangkan dalam penelitian ini, peneliti meneliti produk buku penunjang belajar (buku pendamping) yang memiliki life cycle produk lebih singkat karena terpengaruh dengan kurikulum yang ditetapkan oleh pemerintah yang dapat berubah sewaktu-waktu. Sehingga diskon tidak berpengaruh terhadap keputusan pembelian kembali produk buku pendamping Maestro melainkan standar mutulah yang sangat berpengaruh.

\section{Pengaruh lokasi $\left(\mathrm{X}_{3}\right)$ terhadap keputusan pembelian kembali buku pendamping Maestro} (Y)

Lokasi berpengaruh terhadap keputusan pembelian kembali produk. Hal ini sejalan dengan penelitian Prasetiyo, Pratikto dan Sopiyah (2016) lokasi mempengaruhi keputusan konsumen dalam pemilihan fitness center secara signifikan. Penelitian ini juga sejalan dengan Tyas dan Setiawan (2012) lokasi mempengaruhi keputusan konsumen agar menabung di BMT.

Sesuai dengan lokasi CV Hasan Pratama yang terdapat ditengah kota, serta adanya layanan penunjang untuk mempermudah akes lokasi perusahaan yakni dengan mengakses aplikasi online GPS.

\section{KESIMPULAN DAN SARAN}

\subsection{Kesimpulan}

Penelitian ini membuktikan adanya pengaruh simultan antara variabel standar mutu, diskon dan lokasi terhadap keputusan pembelian kembali buku pendamping Maestro di Wonogiri. Namun secara parsial variabel diskon tidak berpengaruh terhadap keputusan pembelian kembali buku pendamping Maestro di Wonogiri, hal ini dikarenakan buku ajar bergantung pada kurikulum yang ditetapkan oleh pemerintah yang bisa saja berubah sewaktu-waktu. Sehingga standar mutu merupakan hal yang sangat berpengaruh terhadap keputusan pembelian kembali buku pendamping Maestro di Wonogiri.

\subsection{Saran}

Berdasarakan penelitian ini, berikut ini beberapa saran yang penulis berikan untuk perusahaan CV Hasan Pratama: 
(1) CV Hasan Pratama harus senantiasa menjaga standar mutu yang ditetapkan agar dapat menghasilkan produk yang bermutu tinggi.

(2) Berdasarkan wawancara dengan responden, beberapa responden mengeluhkan kualitas kertas yang kurang baik. Sebaiknya CV Hasan Pratama lebih selektif dalam memilah kertas sebagai bahan bakunya, meskipun hal ini dapat berakibat pada meningkatnya HPP produk.

(3) Berdasarkan wawancara dengan responden, beberapa responden menunjukkan bahwa terdapat beberapa kualitas gambar yang kurang baik. Maka sebaiknya CV Hasan Pratama lebih memperhatikan kualitas cetakan gambar yang digunakan, mengingat bahwa cetakan buku ini berwarna hitam putih sehingga penggunaan gambar cukup riskan dalam pengimplementasiannya jika dibandingkan dengan cetakan warna

\section{DAFTAR PUSTAKA}

Anggraeni, F dan Prijati. 2016. Pengaruh Promosi, Diskon dan Impulse Buying terhadap Keputusan Pembelian Hypermarket PTC Surabaya. Jurnal Ilmu dan Riset Manajemen. Vol.5, No.7, Juli 2016: 1-15.

Christanto, G. 2018. Perancangan Sistem Manajemen Mutu ISO 9000:2015 Pada CV Mentari Nusantara. Calyptra: Jurnal Ilmiah Mahasiswa Universitas Surabaya Vol.7, No.1, 2018 .

Fahmi, Irham. 2016. Manajemen Produksi dan Operasi. Bandung: Alfabeta

Ghozali Imam, 2013. Analisis Multivariate dengan program SPSS. Edisi Ke tujuh. Semarang: Badan Penerbit Universitas Diponegoro.

Muhajir, A. 2016. Pengaruh Pengawasan Mutu terhadap Pengambilan Keputusan Konsumen Menggunakan Layanan Jasa Servis Komputer pada CV Eltech Gresik. Jurnal Ekonomi Universitas Kadiri (EkoNika). Vol.01, No.01, April 2016: 62-77.

Prasetiyo, DY, Pratikto, H dan Sopiah. Pengaruh Motif, Lokasi dan Kualitas Layanan terhadap Keputusan Pemilihan Fitness Center (Studi pada Member Fitness Center Best Gym Malang). Jurnal Ekonomi Bisnis. Vol.21, No.1, Maret 2016: 58-69

Putra, Kumadji dan Yulianto. 2016. Pengaruh diskon terhadap minat beli serta dampaknya pada keputusan pembelian (Study pada konsumen yang membeli produk diskon di Matahari Department Store Pasar Besar Malang). Jurnal Administrasi Bisnis (JAB), Vol.38, No.2, September 2016: 184-193.

Satyo, Suprihhadi. 2013. Pengaruh diskon harga, merek produk, dan layanan pelanggan terhadap keputusan pembelian garmen. Jurnal Ilmu dan Riset Manjemen. Vol. 2, No. 8, 2013: $1-19$.

Sudaryono. 2016. Manajemen Pemasaran (Teori dan Implementasi). Yogyakarta: CV Andi Offset. 
Endah Prastiwi, dkk / Edunomika Vol.03, No. 01 (Februari 2019)

Tjiptono, Fandy. 2015. Strategi Pemasaran (Edisi Ke-4). Yogyakarta: Andi.

Tyas, RR dan Setiawan, A. 2012. Pengaruh Lokasi dan Kualitas Pelayanan terhadap Keputusan Nasabah untuk Menabung di BMT Sumber Mulia Tantang. Jurnal Muqtasid, Vol.3, No.2, Desember 2012: 277-297

Widyastutik dan Arianti, RK. 2014. Analisis Strategi Kebijakan Mutu dan Standar Produk Kayu Lapis dalam rangka Meningkatkan Daya Saing Ekspor. Jurnal Agribisnis Indonesia. Vol.2, No.2, Juni 2014: 75-92. 